\title{
Methods and design of a 10-week multi- component family meals intervention: a two group quasi-experimental effectiveness trial
}

Catherine Rogers ${ }^{1}$, Sarah E. Anderson ${ }^{2}$, Jamie S. Dollahite ${ }^{3}$, Tisa F. Hill', Chris Holloman ${ }^{5}$, Carla K. Miller ${ }^{6}$, Keeley J. Pratt ${ }^{7}$ and Carolyn Gunther ${ }^{8^{*}}$ (i)

\begin{abstract}
Background: Given the ongoing childhood obesity public health crisis and potential protective effect of family meals, there is need for additional family meals research, specifically experimental studies with expanded health outcomes that focus on the at-risk populations in highest need of intervention. Future research, specifically intervention work, would also benefit from an expansion of the target age range to include younger children, who are laying the foundation of their eating patterns and capable of participating in family meal preparations. The purpose of this paper is to address this research gap by presenting the objectives and research methods of a 10-week multi-component family meals intervention study aimed at eliciting positive changes in child diet and weight status.

Methods: This will be a group quasi-experimental trial with staggered cohort design. Data will be collected via direct measure and questionnaires at baseline, intervention completion (or waiting period for controls), and 10-weeks post-intervention. Setting will be faith-based community center. Participants will be 60 underserved families with at least 1, 4-10 year old child will be recruited and enrolled in the intervention $(n=30)$ or waitlist control group $(n=30)$. The intervention (Simple Suppers) is a 10-week family meals program designed for underserved families from racial/ethnic diverse backgrounds. The 10, 90-min program lessons will be delivered weekly over the dinner hour. Session components include: a) interactive group discussion of strategies to overcome family meal barriers, plus weekly goal setting for caregivers; b) engagement in age-appropriate food preparation activities for children; and c) group family meal for caregivers and children. Main outcome measures are change in: child diet quality; child standardized body mass index; and frequency of family meals. Regression models will be used to compare response variables results of intervention to control group, controlling for confounders. Analyses will account for clustering by family and cohort. Significance will be set at $p<0.05$.
\end{abstract}

Discussion: This is the first experimentally designed family meals intervention that targets underserved families with elementary school age children and includes an examination of health outcomes beyond weight status. Results will provide researchers and practitioners with insight on evidence-based programming to aid in childhood obesity prevention.

Trial registration: NCT02923050. Registered 03 October 2016. Retrospectively registered.

Keywords: Family meals, Child diet, Weight status, Behavioral intervention, Childhood obesity prevention

\footnotetext{
* Correspondence: gunther.22@osu.edu

${ }^{8}$ Department of Human Sciences, Human Nutrition Program, The Ohio State

University, 313 Campbell Hall, 1787 Neil Avenue, Columbus, OH 43210, USA

Full list of author information is available at the end of the article
}

(c) The Author(s). 2017 Open Access This article is distributed under the terms of the Creative Commons Attribution 4.0 International License (http://creativecommons.org/licenses/by/4.0/), which permits unrestricted use, distribution, and reproduction in any medium, provided you give appropriate credit to the original author(s) and the source, provide a link to the Creative Commons license, and indicate if changes were made. The Creative Commons Public Domain Dedication waiver (http://creativecommons.org/publicdomain/zero/1.0/) applies to the data made available in this article, unless otherwise stated. 


\section{Background}

The American Academy of Pediatrics recommends participation in family meals as a childhood obesity prevention strategy due to the literature demonstrating a protective effect of participation in healthy mealtime routines on child diet and weight [1]. However, the current evidence linking family meals with improved child dietary intake (increased fruit and vegetable intake, decreased sugar-sweetened beverage (SSB) intake) and weight status (decreased body mass index (BMI; (weight $(\mathrm{kg}) /$ height $\left.(\mathrm{m})^{2}\right)$ ) z-score) has significant limitations. The majority of the family meals literature - specifically in the area of childhood obesity prevention - represents observational studies, demonstrating only an associative relationship of family meals with child diet and weight status [2-5]. What's more, racial and ethnic differences have been highly understudied; given that the segment of the United States (US) child population with high prevalence of obesity is racial and ethnic minorities [6], it has been suggested that this is an area in which additional research is needed. Similarly, the existing family meals intervention research (i.e., studies designed specifically to examine the cause and effect relationship between family meals and child diet and weight status), while strong with regard to study design, is limited and primarily targets non-Hispanic White children ( 8 to 12 years old), particularly from well-educated families $[7,8]$. In addition, the majority of the current research fails to examine the child health impact of family meals beyond BMI (e.g., central adiposity and blood pressure (BP)), with only a small number of studies including additional outcomes (e.g., disordered eating) [9-12]. Given the ongoing childhood obesity public health crisis [13] and the potential protective effect of family meals, there is need for additional family meals research, specifically experimental studies with expanded health outcomes that focus on the at-risk populations in highest need of intervention. Future research, specifically intervention work, would also benefit from an expansion of the target age range to include younger children (4-7 year olds), who are laying the foundation of their eating patterns [14], and are capable of participating in family meal preparations [15].

The purpose of this paper is to address this gap in the literature by presenting the objectives and research methods of a 10-week multi-component family meals intervention study, Simple Suppers, aimed at eliciting positive changes in child dietary intake and weight status. The Simple Suppers study is a two group quasi-experimental trial with staggered cohort design that targets underserved families with elementary school age children (4-10 years) and includes an examination of health outcomes beyond weight status.

\section{Methods}

\section{Objectives and hypotheses}

The objectives of this study with related hypotheses will be as follows:

Objective 1. Assess the impact of Simple Suppers on children and caregivers of participating families relative to children and caregivers of families in the control group.

Hypothesis 1.1. Diet quality, BMI z-scores and BMI, waist circumference (WC) z-scores and WC, and $\mathrm{BP}$ z-scores and BP will improve more from baseline to post-intervention among children and caregivers, respectively, participating in the intervention than in the controls.

Hypothesis 1.2. Diet quality, BMI z-scores and BMI, WC $\mathrm{z}$-scores and $\mathrm{WC}$, and BP $\mathrm{z}$-scores and BP improvements will be maintained during the follow-up period among children and caregivers, respectively, participating in the intervention.

Objective 2. Assess the impact of Simple Suppers on the family meals environment of participating families relative to the controls.

Hypothesis 2.1. Frequency of family meals (breakfast and dinner), TV viewing during meals, and eating family meals in a dining area will improve more from baseline to post-intervention among families participating in the intervention than in the controls.

Hypothesis 2.2. Frequency of family meals (breakfast and dinner), TV viewing during the meals, and eating family meals in a dining area improvements will be maintained during the follow-up period among families participating in the intervention.

\section{Study design}

The study will be implemented over 12-months as a twogroup (intervention; waitlist control) quasi-experimental trial using a staggered cohort design (Table 1). At each of three time periods, separated by 10 weeks, a cohort of 20 families will be recruited. Each cohort will be divided into an intervention and waitlist control group (10 families in each). Consequently, a total of 60 families (30 in the intervention group and 30 in the waitlist control group) will be enrolled. Upon confirmation of study eligibility, a baseline data collection appointment will be scheduled at the participating family's home or the community center during the two weeks preceding intervention commencement. Data will be collected on the primary food preparing caregiver and all children 4-10 years old. Written caregiver consent and child assent will be obtained. Data will be 
Table 1 Simple Suppers Intervention Study Design: Two-Group, Staggered Cohort Quasi-Experimental Design

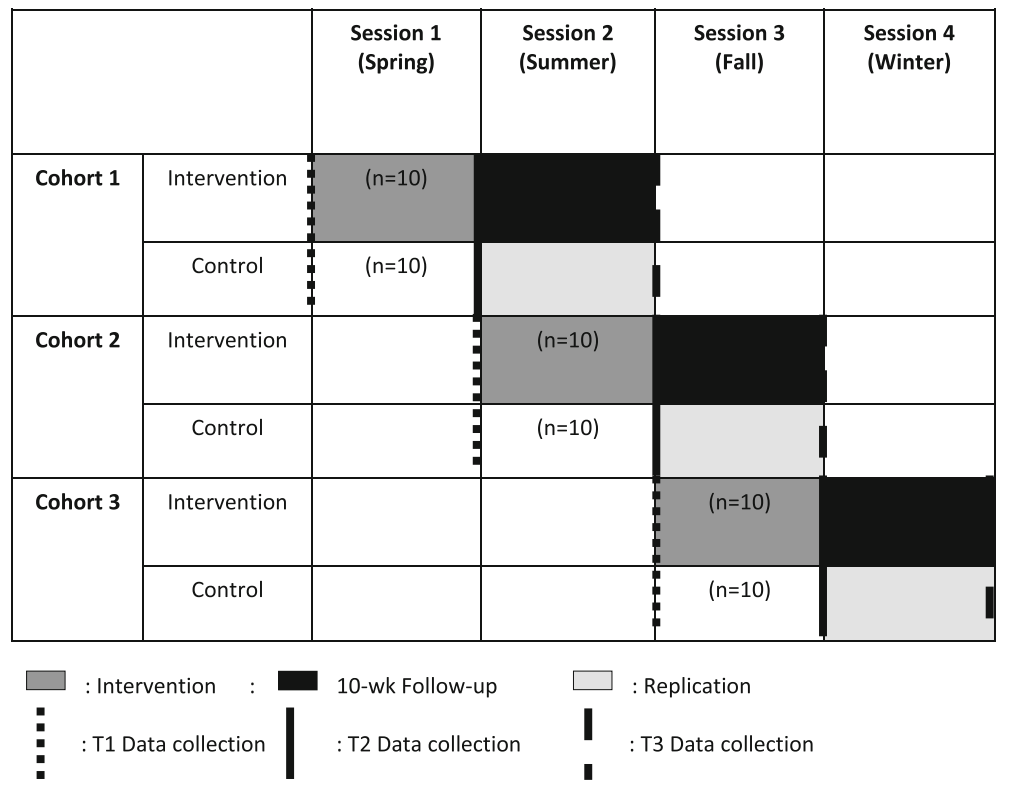

collected on all outcomes via direct measure and questionnaires at baseline (time point 0 , T0), 10-week post-test (time point 1, T1), and 10-week follow-up (time point 2, T2). Repeatability of the intervention (replication) will be evaluated by assessing measures on the waitlist control group at T1 and T2. Assessments will last up to $90 \mathrm{~min}$. A team of trained research staff, blinded from group assignment, will facilitate data collection. Caregiver participants will receive a $\$ 25$ grocery store gift card at each data collection point for their participation in the research. All study materials and procedures have been approved by the Institutional Review Board at Ohio State University.

Following baseline data collection, families will decide whether to enroll in either the upcoming 10-week session of Simple Suppers (intervention group) or to wait for 10-weeks (waitlist control group) after which time they would begin the Simple Suppers program. Randomization of families is not feasible because of scheduling conflicts with participating families, the desire of families to participate in the program with families they know, and the need to establish trust with the site/participating families; thus, to preserve sample size and establish trust with the site/participating families, the personal preference of participating families will determine group membership.

\section{Setting}

A faith-based community center will serve as the setting for the Simple Suppers intervention. The question of "who is my neighbor?" is central to the mission and ministries of the center, which has approximately 10,000 visits per month for programming. The most recent service area census tracts demonstrate the following statistics in the center's immediately surrounding neighborhoods: median household income is $\$ 32,307$ to $\$ 58,490$, compared to $\$ 51,890$ in the broader county; number of families falling below the poverty line ranges from $10.7 \%$ to $24.9 \%$, compared to $13.2 \%$ in the broader county; higher percentage of racial and ethnic minorities than the county as a whole, with $41.8 \%$ being Black compared to 21.2 in the county; and a high percentage of households that are families (58.7\%).

\section{Participants}

Participants will be recruited in-person at community center events, center newsletter advertisements, and posters displayed in center. Information on recruitment materials will direct interested families to contact the research team for a screening evaluation to determine study eligibility. To be eligible for inclusion, caregivers should be the primary food preparer in the home; be responsible for at least one child 4-10 years of age; speak English as the primary language in the home; and have lived in the U.S. for at least one year. Families with one or more family members following a restrictive or therapeutic diet will be excluded.

\section{Intervention}

The Intervention Mapping protocol was utilized in the development of the Simple Suppers intervention [16, 17]. Formulation of proximal program objectives occurred as the first step in the mapping process. Based on the current evidence linking family meals with improved child diet and weight status [2-5], the following program objectives 
were formulated: 1) 'Increase frequency of family meals prepared in the home ( $\geq 5$ days/week)' and 2) 'Improve child diet quality (significantly increase Healthy Eating Index (HEI) score $(p<0.05)$; increase servings of fruits and vegetables to meet Dietary Guidelines recommendations; significantly decrease daily servings of sugar sweetened beverages $(p<0.05)^{\prime}$ (Table 2$)$.

Matrices containing the behavioral performance objectives relating to each program objective were created for each level of intervention: individual (child) and interpersonal (caregiver) (Table 2). Development of the performance objectives were guided by the evidence-based 2010 Dietary Guidelines for Americans guidelines for families and children [18]. For example, under program objective 1) (family meals), the performance objective at the individual (child) level was 'Children participate in cooking activities' and at the interpersonal (caregiver) level, 'Caregivers identify health benefits of regular family meals prepared in the home'.

After formulation of performance objectives, a list of personal determinants for each performance objective was generated based on the theoretical foundation of the Simple Suppers program - the Social Cognitive Theory, which posits that behavior change is a function of a reciprocal relationship between personal (e.g., behavioral capabilities and cognitive factors, such as self-efficacy and self-evaluation) and environmental (e.g., norms, modeling, and reinforcement) factors [19, 20]. Next, personal determinants were selected for children at the individual level and caregivers at the interpersonal level based on importance (i.e., strength of the association of the determinant with the behavior) and changeability (i.e., likelihood that the intervention may impact the determinant) [16]. The personal determinants included: behavioral capability; self-efficacy; self-evaluation; and norms, modeling, and reinforcement (Table 3). The performance objectives were then crossed with the selected determinants, which resulted in matrices of change objectives (Tables 3 and 4). The change objectives stated precisely what needs to change in the determinants' behavioral outcomes in order to accomplish the performance objectives. They were developed using action words and followed by a statement of what is expected to result from the intervention [16, 17]. Because two target groups were selected, two difference matrices of change were developed under each program objective. For example, for program objective 1) (family meals), on the individual (child) level, the performance objective for children that stated 'Children participate in meal preparation activities' was crossed with the determinant 'behavioral capability, which resulted in the change objective that 'children practice cooking skills during Simple Suppers and at home'. An example on the interpersonal (caregiver) level, also for program objective 1) (family meals), is as

Table 2 Overview of formulated program objectives at each level of intervention

\begin{tabular}{|c|c|c|c|}
\hline Program objective & Level of Intervention & Target group & Performance Objectives \\
\hline \multirow{2}{*}{$\begin{array}{l}\text { 1. Increase frequency of family meals } \\
\text { prepared in the home ( } \geq 5 \text { days/week) }\end{array}$} & Individual & Child & PO1. Children participate in cooking activities \\
\hline & Interpersonal & Caregiver & $\begin{array}{l}\text { PO2. Caregivers identify health benefits of regular } \\
\text { family meals prepared in the home } \\
\text { PO3. Caregivers plan well-balanced weekly dinner } \\
\text { menus that include } \geq 1 \text { svg from } 3 \text { of the } 5 \text { food } \\
\text { groups } \\
\text { PO4. Caregivers plan when and where family meals } \\
\text { will be served in the home } \\
\text { PO5. Caregivers use list for grocery shopping } \\
\text { PO6. Caregivers use cost-saving strategies for family } \\
\text { meals in the home } \\
\text { PO7. Caregivers use time-saving strategies for family } \\
\text { meals in the home }\end{array}$ \\
\hline
\end{tabular}

2. Improve child diet quality (significantly

increase HEI score $(p<0.05)$; increase daily svgs of fruits, vegetables to Dietary

Guidelines recommendations; ${ }^{b}$ significantly

decrease daily svgs of: SSBs $(p<0.05$

decrease $)^{c}$
Individual Child

Interpersonal Caregiver
PO1. Children know health benefits of eating well-balanced meals and snacks $\mathrm{PO} 2$. Children participate in planning/preparing well-balanced family meals $\geq 2 x /$ week

PO3. Caregivers know benefits of serving wellbalanced meals/snacks

PO4. Caregivers serve family meal in the home that include $\geq 1 \mathrm{svg}$ from 3 of the 5 food groups $\geq 1 \times /$ week

PO5. Caregivers serve $\geq 3$ snacks/week that include $\geq 1$ serving from 2 food groups

PO6. Caregivers buy food for planned meals/snacks at grocery store

\footnotetext{
PO: Performance objective HEl: Healthy Eating Index SSB: Sugar sweetened beverage Svg: Serving

a Measured by asking the question, "During the past 7 days, how many times did all or most, of your family eat dinner together?" [7]

bU.S. Departments of Agriculture and Health and Human Services. Dietary Guidelines for Americans, 2010. 7th ed., Washington, DC. December, 2010 [18]

${ }^{\mathrm{c}}$ Measured by 24-h dietary recall [29]
} 
Table 3 Matrix of change objectives by level of intervention for program objective 1 of the simple suppers intervention Program objective 1: Increase frequency of family meals prepared in the home ( $\geq 5$ days/week $)^{a}$

\begin{tabular}{|c|c|c|c|c|c|}
\hline \multirow[t]{2}{*}{ Level of intervention } & \multirow{2}{*}{$\begin{array}{l}\text { Performance } \\
\text { objectives }\end{array}$} & \multicolumn{4}{|l|}{ Personal determinants } \\
\hline & & Behavioral capability & Self-efficacy & Self-evaluation & $\begin{array}{l}\text { Norms, modeling, } \\
\text { reinforcement }\end{array}$ \\
\hline Individual (child) & $\begin{array}{l}\text { PO1. Children } \\
\text { participate in meal } \\
\text { preparation activities }\end{array}$ & $\begin{array}{l}\text { CO1.1.1 Children } \\
\text { practice cooking skills } \\
\text { during Simple } \\
\text { Suppers and at home } \\
\text { CO1.1.2 Children are } \\
\text { able to participate in } \\
\text { age-appropriate cook- } \\
\text { ing activities at Simple } \\
\text { Suppers and at home }\end{array}$ & $\begin{array}{l}\text { CO2.1 Children } \\
\text { express confidence in } \\
\text { participating in } \\
\text { cooking activities }\end{array}$ & $\begin{array}{l}\text { CO3.1 Children are } \\
\text { able to determine if } \\
\text { they meet their } \\
\text { weekly goal for } \\
\text { participating in } \\
\text { cooking at home }\end{array}$ & $\begin{array}{l}\text { CO4.1.1 Children } \\
\text { participate in cooking } \\
\text { activities at Simple } \\
\text { Suppers family meals } \\
1 \times / \text { week } \\
\text { CO4.1.2 Children } \\
\text { increase their } \\
\text { participation in } \\
\text { cooking at home to } \\
\geq 1 \times / \text { week in the } \\
\text { home }\end{array}$ \\
\hline
\end{tabular}

Interpersonal (caregiver)
PO2. Caregivers identify health benefits of regular family meals prepared in the home

PO3. Caregivers plan well-balanced weekly dinner menus that include $\geq 1 \mathrm{svg}$ from 3 of the 5 food groups

PO4. Caregivers plan when and where family meals will be served at home

PO5. Caregivers use list for grocery shopping

P06. Caregivers use cost-saving strategies for family meals at home

PO7. Caregivers use time-saving strategies for family meals at home
C01.2.1 Caregivers identify barriers to family meals at home CO1.2.2 Caregivers know benefits of regular family meals prepared at home

C01.3.1 Caregivers know importance of planning/serving wellbalanced dinner menus

C01.3.2 Caregivers know how to plan/ serve well-balanced family meals at home

C01.4.1 Caregivers know importance of mealtime routines CO1.4.2 Caregivers know strategies to minimize mealtime distractions

C01.4.3 Caregivers plan/establish family mealtime routines

CO1.5.1 Caregivers know benefits of using a grocery list C01.5.2 Caregivers know how to develop grocery list using planned family meals

C01.6 Caregivers know how to use cost-saving strategies to plan/prepare family meals at home

CO1.7 Caregivers know how to use time-saving strategies to plan/prepare family meals at home
CO2.3 Caregivers express confidence in planning/serving wellbalanced family meals

CO2.4.1 Caregiver expresses confidence in establishing mealtime routines at home

CO2.4.2 Caregiver expresses confidence in minimizing mealtime distractions

CO2.5.1 Caregivers express confidence about developing grocery list

CO2.5.2 Caregivers express confidence in using list for grocery shopping

CO2.6 Caregivers express confidence in preparing and serving family meals at home on a budget

CO2.7 Caregivers express confidence in preparing and servings family meals at home when time is limited
CO3.3 Caregivers are able to determine if they meet their weekly goal for planning/serving wellbalanced family meals at home

C04.3.1 Caregivers learn to plan, prepare and serve wellbalanced family meals from Simple Suppers Educators C04.3.2 Caregivers plan, prepare and serve $\geq 1$ wellbalanced family meal at home each week

C03.4.1 Caregivers able to determine if family mealtime routines are being established

C03.4.2 Caregivers able to determine if mealtime distractions are minimized

CO3.5 Caregivers able to determine if they meet their goal to develop and use a list for grocery shopping
CO4.4 Caregivers guided by Simple Suppers Educators in establishing family mealtime routines during Simple meals

CO4.5 Caregivers develop weekly grocery list for planned family meals Suppers group family 
Table 4 Matrix of Change Objectives by Level of Intervention for Program Objective 2 of the Simple Suppers Intervention

Program objective: Improve child diet quality (significantly increase HEI score $(p<0.05)$; increase daily svgs of fruits, vegetables to Dietary Guidelines recommendations; significantly decrease daily svgs of: SSBs $\left(p<0.05\right.$ decrease) ${ }^{a}$

\begin{tabular}{|c|c|c|c|c|c|}
\hline \multirow[t]{2}{*}{ Level of intervention } & \multirow{2}{*}{$\begin{array}{l}\text { Performance } \\
\text { objectives }\end{array}$} & \multicolumn{4}{|l|}{ Personal determinants } \\
\hline & & Behavioral capability & Self-efficacy & Self-evaluation & $\begin{array}{l}\text { Norms, modeling, } \\
\text { reinforcement }\end{array}$ \\
\hline \multirow[t]{2}{*}{ Individual (child) } & $\begin{array}{l}\text { PO1. Children know } \\
\text { health benefits of } \\
\text { eating well-balanced } \\
\text { meals/snacks }\end{array}$ & $\begin{array}{l}\text { CO1.1 Children know } \\
\text { health benefits of } \\
\text { eating a variety of } \\
\text { nutritious foods }\end{array}$ & $\begin{array}{l}\text { CO2.1 Children express } \\
\text { confidence in knowing } \\
\text { health benefits of } \\
\text { eating well-balanced } \\
\text { meals/snacks }\end{array}$ & & \\
\hline & $\begin{array}{l}\text { PO2. Children } \\
\text { participate in planning/ } \\
\text { preparing well- } \\
\text { balanced family meals/ } \\
\text { snacks } \geq 2 \times \text { week }\end{array}$ & $\begin{array}{l}\text { CO1.2.1 Children can } \\
\text { identify food group } \\
\text { sources in meals/snacks } \\
\text { c01.2.2 Children are } \\
\text { able to perform age- } \\
\text { appropriate coking skills }\end{array}$ & $\begin{array}{l}\text { CO2.2 Children } \\
\text { express confidence in } \\
\text { participating in meal/ } \\
\text { snack planning/ } \\
\text { preparation }\end{array}$ & $\begin{array}{l}\text { CO3.2 Children are } \\
\text { able to determine if } \\
\text { they meet their } \\
\text { weekly goal for } \\
\text { participating in family } \\
\text { meal/snack } \\
\text { preparation }\end{array}$ & $\begin{array}{l}\text { CO4.2.1 Children } \\
\text { participate in cooking } \\
\text { a well-balanced family } \\
\text { meal/snack with peers } \\
\text { of the same age } 1 \times / \\
\text { week during Simple } \\
\text { Suppers } \\
\text { cO4.2.2 Children } \\
\text { participate in cooking } \\
\text { well-balanced family } \\
\text { meals/snacks at home } \\
\geq 1 x / \text { week }\end{array}$ \\
\hline
\end{tabular}

Interpersonal (caregiver)
PO3. Caregivers know benefits of serving well-balanced meals/ snacks

PO4. Caregivers serve a family meal that includes $\geq 1$ serving from 3 of the 5 food groups $\geq 1 x /$ week

PO5. Caregivers serve $\geq 3$ snacks/week that include $\geq 1$ serving from 2 food groups

PO6. Caregivers buy food for planned meals/snacks at grocery store
C01.3.1 Caregivers identify barriers to offering well-balanced meals/snacks and know strategies to overcome identified barriers C01.3.2 Caregivers know short- and long-term consequences of not serving well-balanced meals/snacks

CO1.4.1 Caregivers know importance of including a variety of foods in meals CO1.4.2 Caregivers know $\geq 2$ strategies to incorporate foods from 3 food groups into family meals

C01.5.1 Caregivers know importance of eating/serving wellbalanced snacks C01.5.2 Caregivers are able to plan $\geq 3$ snacks/week that include $\geq 1$ serving from 2 food groups

CO1.6.1 Caregivers plan well-balanced family meals and snacks C01.6.2 Caregivers prepare grocery list using planned meals/ snacks

CO2.3 Caregivers express confidence in knowing benefits of serving well-balanced meals/snacks

CO2.4 Caregivers express confidence in planning/preparing well-balanced family meals

CO2.4.2 Caregivers express confidence in eating/serving wellbalanced family meals

CO2.5.1 Caregivers express confidence in planning wellbalanced snacks CO2.5.2 Caregivers express confidence in eating/serving wellbalanced snacks

CO2.6.1 Caregivers express confidence in developing grocery list CO2.6.2 Caregivers express confidence in using list for grocery shopping
C03.4.1 Caregivers set goal to serve a family meal that includes $\geq 1$ serving from 3 of the 5 food groups $\geq 1 \mathrm{x} /$ week C03.4.2 Caregivers monitor goal progress and determine if meeting established goal

CO3.5.1 Caregivers set goal to serve $\geq 3$ snacks/week that include $\geq 1$ serving from 2 food groups C03.5.2 Caregivers monitor goal progress and determine if meeting established goal

CO3.6.1 Caregivers set goal to develop and use list for grocery shopping each week CO3.6.2 Caregivers monitor goal progress and determine if meeting established goal
CO4.4 Caregivers plan $\geq 1$ family meal/week that includes $\geq 1$ serving from 3 of the 5 food groups

C04.5 Caregivers plan $\geq 3$ snacks/week that include $\geq 1$ serving from 2 food groups

C04.6 Using list for grocery shopping becomes norm for caregivers 
follows: the performance objective for caregivers that stated 'Caregivers identify health benefits of regular family meals prepared in the home' was crossed with the determinant 'behavioral capability', which resulted in the change objective that 'Caregivers know benefits of regular family meals prepared at home.'

Next, theory-based methods to influence change in the determinants at the individual (child) and interpersonal (caregiver) level were selected based on the theoretical framework of the intervention (Social Cognitive Theory) $[19,21]$ and in reference to methods described by Bartholomew et al. [16, 17]. For identifying theory-based methods to influence determinants at the interpersonal (caregiver) level, the Adult Learning Theory, which purports that adult learning is most effective when a collaborative, problem-based approach was also referenced $[22,23]$. A list of all change objectives that were linked with a specific determinant was made, and the theoretical methods were then matched with the corresponding determinant (Table 5). Finally, practical strategies were designed to put the theoretical methods into practice (Table 5). For example, under the family meals program objective, on the individual (child) level, the result of crossing the performance objective 'children participate in meal preparation activities' with the determinant 'behavioral capability' was the change objective 'children are able to participate in ageappropriate cooking skills'. The selected theory-based method that corresponded to the determinant 'behavioral capability' in order to achieve the change objective was facilitation. This theory-based method was then translated into a practical strategy. In this case, a practical strategy that was chosen for the method facilitation was to 'Learn age appropriate cooking skills at each Simple Suppers lesson'. An example on the interpersonal (caregiver) level, also under the family meals program objective, (caregiver) level is as follows: the result of crossing the performance objective 'Caregivers identify health benefits of regular family meals prepared in the home' with the determinant behavioral capability was the change objective 'Caregivers know benefits of regular family meals prepared at home'. The selected theory-based method that corresponded to the determinant behavioral capability in order to achieve the change objective was active learning. This theory-based method was then translated into a practical strategy. In this case, a practical strategy that was chosen for the method active learning was: 'Educators use the 4A method (participants think about their experience with a topic (Anchor), learn new information (Add), reinforce learning through hands-on activities (Apply), and set goals to utilize new knowledge at home (Away)) to lead weekly caregiver discussions [23, 24].

The next step was to develop the Simple Suppers curriculum in direct reference to the results produced from the aforementioned Intervention Mapping (Table 6). The initial draft was reviewed by field experts using a nutrition education curriculum assessment tool [25]. Curriculum modifications were then made using reviewer feedback (e.g., incorporating additional handson learning activities in the caregiver component to enhance interactive nature of curriculum), after which additional pilot testing occurred and subsequent curricular revisions were made [26].

Finally, the Simple Suppers program design was developed with feedback from program adopters (faith-based community center staff), implementers, and the target population [27] (e.g., utilizing two (versus one) educators for the caregiver component and incorporating sitebased staff into the staffing structure). Each 90-min lesson is delivered weekly over the dinner hour. Session components include: a) interactive group discussion and goal setting with caregivers; b) hands-on activities with children; and c) group family meal with caregivers and children.

\section{Outcome measures \\ Children and caregivers}

Diet quality Dietary intake will be assessed by conducting three, nonconsecutive (two weekdays, one weekend day) 24-h $(24 \mathrm{~h})$ dietary recalls using USDA's 5-step multi-pass dietary recall method [28]. At each data collection time point, the first dietary recall will be conducted during the in-person data collection visit, the remaining two will be conducted via telephone within two weeks of the initial in-person recall. For the child dietary recalls, caregivers will provide assistance, as caregiver-assisted $24 \mathrm{~h}$ recalls, collected in this way (i.e., relying on three days and utilizing the multi-pass method), provide the most accurate estimate of dietary intake among children 4 to 11 years of age [29]. Caregiver $24 \mathrm{~h}$ dietary recalls will be conducted independently following the child recall(s). Typical daily dietary intake will be determined by averaging dietary intake across the three recalls at each time point to determine daily servings of fruit, vegetables, and SSB. Diet quality will be assessed at each point by calculating a Healthy Eating Index 2010 score using the three $24 \mathrm{~h}$ dietary recalls collected [30].

Anthropometric assessments Standardized procedures will be used to assess height and weight on all participating children and caregivers via calibrated stadiometers (Hopkins portable road rod stadiometer) and scales (BFHA-B400SV digital scale), respectively [31, 32]. Body mass index will be calculated using measured heights and weights. Centers for Disease Control and Prevention (CDC) age- and sex-adjusted BMI growth charts will be used to determine BMI $\mathrm{z}$-scores for children to adjust for expected healthy growth and 
Table 5 Theory-based methods and practical strategies to achieve the change objectives for selected program objectives of the simple suppers intervention

\begin{tabular}{|c|c|c|c|c|c|c|}
\hline Program objective & $\begin{array}{l}\text { Level of } \\
\text { intervention }\end{array}$ & Determinant & Change objective & Theory-based method & Theory & Practical strategy \\
\hline \multirow[t]{11}{*}{$\begin{array}{l}\text { 1. Increase frequency } \\
\text { of family meals } \\
\text { prepared in the home } \\
(\geq 5 \text { days/week })^{a}\end{array}$} & $\begin{array}{l}\text { Individual } \\
\text { (child) }\end{array}$ & $\begin{array}{l}\text { Behavioral } \\
\text { capability }\end{array}$ & CO1.1.1, CO1.1.2 & - Facilitation & $\cdot \mathrm{SCT}$ & $\begin{array}{l}\text { - Learn new age-appropriate } \\
\text { cooking skills at each Simple } \\
\text { Suppers lesson } \\
\text { - Discuss food safety and } \\
\text { cleanup with Educators }\end{array}$ \\
\hline & & & CO1.1.1, CO1.1.2 & - Vicarious learning & $\cdot \mathrm{SCT}$ & $\begin{array}{l}\text { - Children divided into three } \\
\text { age groups (4-5 years olds; } \\
6-8 \text { years olds; } 9-10 \text { year } \\
\text { olds) for nutrition education } \\
\text { \& engagement in food } \\
\text { preparation }\end{array}$ \\
\hline & & & CO1.1.1, CO1.1.2 & - Mastery experience & $\cdot$ SCT & $\begin{array}{l}\text { - Learned food prep skills } \\
\text { accrued/practiced over } \\
\text { lessons }\end{array}$ \\
\hline & & Self-efficacy & $\mathrm{CO} 2.1$ & • Facilitation & $\cdot \mathrm{SCT}$ & $\begin{array}{l}\text { - Educators provide guidance } \\
\text { \& feedback as children learn/ } \\
\text { practice food prep skills }\end{array}$ \\
\hline & & & $\mathrm{CO} 2.1$ & - Vicarious learning & $\cdot \mathrm{SCT}$ & $\begin{array}{l}\text { - Participate in cooking } \\
\text { activities with peers of the } \\
\text { same age }\end{array}$ \\
\hline & & & $\mathrm{CO} 2.1$ & - Mastery experience & $\cdot \mathrm{SCT}$ & $\begin{array}{l}\text { - Practice cooking skills } \\
\text { learned during Simple } \\
\text { Suppers at home }\end{array}$ \\
\hline & & Self-evaluation & CO3.1 & - Self-monitoring & $\cdot \mathrm{SCT}$ & $\begin{array}{l}\text { - Establish weekly goal during } \\
\text { Simple Suppers to practice } \\
\text { newly learned cooking skill } \\
\text { at home } \\
\text { - Weekly goals are reinforced } \\
\text { by sharing goal with } \\
\text { caregivers during Simple } \\
\text { Suppers family meal }\end{array}$ \\
\hline & & & CO3.1 & • Feedback & $\cdot \mathrm{SCT}$ & $\begin{array}{l}\text { - Discuss cooking skills used } \\
\text { at home during past week } \\
\text { with Educators and peers } \\
\text { during Simple Suppers }\end{array}$ \\
\hline & & $\begin{array}{l}\text { Norms, } \\
\text { modeling, } \\
\text { reinforcement }\end{array}$ & CO4.1.1, CO4.1.2 & - Facilitation & $\cdot \mathrm{SCT}$ & $\begin{array}{l}\text { - Engage in family meal } \\
\text { cooking activities with peers } \\
\text { and Educators during } \\
\text { Simple Suppers } \\
\text { - Decorate/wear aprons for } \\
\text { food prep during Simple } \\
\text { Suppers and at home } \\
\text { - Share cooking skills learned } \\
\text { each week with caregivers } \\
\text { at start of Simple Suppers } \\
\text { group family meals } \\
\text { - Lead cleanup at Simple } \\
\text { Suppers family meals } \\
\text { - Families receive take-home } \\
\text { cooking utensil during each } \\
\text { Simple Suppers lesson }\end{array}$ \\
\hline & & & CO4.1.1, CO4.1.2 & - Mastery experience & $\cdot$ SCT & $\begin{array}{l}\text { - Repeated engagement in } \\
\text { family meal cooking during } \\
\text { Simple Suppers } \\
\text { - Weekly goal established to } \\
\text { engage in family meal food } \\
\text { prep at home }\end{array}$ \\
\hline & $\begin{array}{l}\text { Interpersonal } \\
\text { (caregiver) }\end{array}$ & $\begin{array}{l}\text { Behavioral } \\
\text { capability }\end{array}$ & $\begin{array}{l}\text { CO1.2.1, CO1.2.2, } \\
\text { CO1.3.1, CO1.3.2, } \\
\text { CO1.4.1, CO1.4.2, }\end{array}$ & - Active learning & $\cdot A L T$ & $\begin{array}{l}\text { - Educators use } 4 \text { A method } \\
\text { to lead weekly caregiver } \\
\text { discussions }\end{array}$ \\
\hline
\end{tabular}


Table 5 Theory-based methods and practical strategies to achieve the change objectives for selected program objectives of the simple suppers intervention (Continued)

\begin{tabular}{|c|c|c|c|c|}
\hline & $\begin{array}{l}\text { CO1.4.3, CO1.5.1, } \\
\text { CO1.5.2, CO1.6, CO1.7 }\end{array}$ & & & $\begin{array}{l}\text { - Educators engage caregivers } \\
\text { in games, meal planning \& } \\
\text { goal-setting related to } \\
\text { weekly lesson topics }\end{array}$ \\
\hline & $\begin{array}{l}\text { CO1.3.2, CO1.4.2, } \\
\text { CO1.4.3, CO1.5.2, } \\
\text { CO1.6, CO1.7 }\end{array}$ & - Facilitation & $\cdot$ SCT & $\begin{array}{l}\text { - Educators provide resources } \\
\text { (e.g., recipe book, coupons, } \\
\text { store ads) to plan family } \\
\text { meals using skills learned at } \\
\text { each lesson }\end{array}$ \\
\hline & $\begin{array}{l}\text { CO1.2.1, CO1.2.2, } \\
\text { CO1.3.2, CO1.4.2, } \\
\text { CO1.4.3, CO1.5.2, } \\
\text { CO1.6, CO1.7 }\end{array}$ & - Problem solving & $\cdot$ ALT & $\begin{array}{l}\text { - Caregivers set weekly goals } \\
\text { \& discuss successes/ } \\
\text { challenges with meeting } \\
\text { goals with Educators \& } \\
\text { other caregivers } \\
\text { - Educators \& caregivers } \\
\text { provide suggestions to help } \\
\text { peer caregivers overcome } \\
\text { challenges preventing them } \\
\text { from reaching their goals }\end{array}$ \\
\hline & $\begin{array}{l}\text { CO1.2.1, CO1.2.2, } \\
\text { CO1.3.1, CO1.3.2, } \\
\text { CO1.4.1, CO1.4.2, } \\
\text { CO1.4.3, CO1.5.1, } \\
\text { CO1.5.2, CO1.6, CO1.7 }\end{array}$ & - Vicarious learning & $\cdot$ SCT & $\begin{array}{l}\text { - Caregivers acquire new } \\
\text { knowledge through peer } \\
\text { discussions } \\
\text { - Caregivers participate in } \\
\text { games, goal-setting \& menu } \\
\text { planning with peer } \\
\text { caregivers }\end{array}$ \\
\hline & $\begin{array}{l}\text { CO1.3.2, CO1.4.3, } \\
\text { CO1.5.2, CO1.6, CO1.7 }\end{array}$ & - Mastery experience & $\cdot$ SCT & $\begin{array}{l}\text { - Caregivers plan } \geq 1 \text { family } \\
\text { meal using skills learned } \\
\text { each week to practice skills } \\
\text { at home }\end{array}$ \\
\hline Self-efficacy & $\begin{array}{l}\mathrm{CO} 2.3, \mathrm{CO} 2.4 .1 \\
\mathrm{CO} 2.4 .2, \mathrm{CO} 2.5 .1 \\
\mathrm{CO} 2.5 .2, \mathrm{CO} 2.6, \mathrm{CO} 2.7\end{array}$ & - Feedback & $\cdot$ SCT & $\begin{array}{l}\text { - Discuss challenges and } \\
\text { successes with weekly } \\
\text { family meals goal. } \\
\text { - Problem solve with peers to } \\
\text { overcome challenges }\end{array}$ \\
\hline & $\begin{array}{l}\mathrm{CO} 2.3, \mathrm{CO} 2.4 .1 \\
\mathrm{CO} 2.4 .2, \mathrm{CO} 2.5 .1 \\
\mathrm{CO} 2.5 .2, \mathrm{CO} 2.6, \mathrm{CO} 2.7\end{array}$ & - Social support & $\cdot$ SCT & $\begin{array}{l}\text { - Post goal successes and } \\
\text { challenges throughout } \\
\text { week on Simple Suppers } \\
\text { Facebook page. Peers and } \\
\text { Educators provide praise/ } \\
\text { support/encouragement }\end{array}$ \\
\hline & $\begin{array}{l}\mathrm{CO} 2.3, \mathrm{CO} 2.4 .1 \\
\mathrm{CO} 2.4 .2\end{array}$ & - Modeling & $\cdot$ SCT & $\begin{array}{l}\text { - Caregivers plan family meals } \\
\text { for upcoming week with } \\
\text { peer caregivers during } \\
\text { weekly lessons } \\
\text { - Caregivers observe } \\
\text { Educators facilitating group } \\
\text { family meal during weekly } \\
\text { lessons }\end{array}$ \\
\hline & $\begin{array}{l}\mathrm{CO} 2.3, \mathrm{CO} 2.4 .1 \\
\mathrm{CO} 2.4 .2\end{array}$ & - Mastery experience & $\cdot$ SCT & $\begin{array}{l}\text { - Caregivers participate in } \\
\text { group family meals during } \\
\text { weekly lessons } \\
\text { - Caregivers plan and set } \\
\text { weekly goals to have family } \\
\text { meals at home }\end{array}$ \\
\hline Self-evaluation & $\begin{array}{l}\text { CO3.3, CO3.4.1, } \\
\text { C03.4.2, CO3.5 }\end{array}$ & • Self-monitoring & $\cdot$ SCT & $\begin{array}{l}\text { - Set individualized weekly } \\
\text { SMART goals aligned with } \\
\text { lesson topics }\end{array}$ \\
\hline & $\begin{array}{l}\text { CO3.3, CO3.4.1, } \\
\text { CO3.4.2, CO3.5 }\end{array}$ & - Feedback & $\cdot$ SCT & $\begin{array}{l}\text { - Goals are reinforced by } \\
\text { caregivers sharing their } \\
\text { weekly goals }\end{array}$ \\
\hline
\end{tabular}


Table 5 Theory-based methods and practical strategies to achieve the change objectives for selected program objectives of the simple suppers intervention (Continued)

- Educators and peers provide feedback/assure appropriateness

- Discuss previous week's goal successes and challenges at beginning of each lesson. Caregivers problem solve together to overcome challenges

Norms, $\quad$ CO4.3.1, CO4.3.2, $\quad$ Facilitation $\quad$ • SCT $\quad \cdot$ Simple Suppers group $\begin{array}{ll}\text { modeling, } \quad \mathrm{CO} 4.4, \mathrm{CO} 4.5 & \text { family meals follow routine/ } \\ \text { reinforcement } & \text { establish norm for family }\end{array}$ $\begin{array}{ll}\text { reinforcement } & \text { establish } \\ \text { meals } & \text { Provide }\end{array}$

- Provide weekly take-home cooking utensil to facilitate cooking at home

CO4.4

- Mastery experience

- SCT

- Educators guide caregivers in establishing mealtime routine during Simple

Improve child diet quality (significantly Individual (child)

Behavioral

C01.2.1

- Facilitation

$\cdot$ SCT

capability

increase HEl score

$(p<0.05)$; increase

daily svgs of fruits,

vegetables to Dietary

Guidelines

recommendations;

significantly decrease

daily svgs of: SSBs

$(p<0.05 \text { decrease })^{b}$

\section{Suppers and at home}

- Before Simple Suppers family meals, children name foods from each food group in the upcoming family meal
CO1.1, CO1.2.2

CO1.1, CO1.2.2

Self-efficacy

$\mathrm{CO} 2.1, \mathrm{CO} 2.2$

$\mathrm{CO} 2.2$

Self-evaluation
• Vicarious learning

$\cdot$ SCT

Mastery experience

$\cdot$ SCT

- Facilitation

$\cdot$ SCT

- Vicarious learning

$\cdot$ SCT

- Self-monitoring $\cdot$ SCT
- Discuss food groups and benefits of healthy eating with Educators and peers at Simple Suppers

- Learn to cook a variety of foods with peers

- Children learn food prep skills \& become familiar with a variety of food while helping prepare Simple Suppers family meals

- Learn health benefits of foods through interactive discussions \& food prep

- Engage in planning/ preparing well-balanced meals/snacks during Simple Suppers and at home $\geq 2 x /$ week

- Engage in food prep with peers of the same age

- Eat Simple Suppers group family meals with peers

- Establish weekly goal during Simple Suppers to try a new food at home

- Weekly goal reinforced by sharing goal with caregivers during Simple Suppers family meal 
Table 5 Theory-based methods and practical strategies to achieve the change objectives for selected program objectives of the simple suppers intervention (Continued)

CO3.2

orms,

modeling,

reinforcement
Interpersonal

(caregiver)
Behavioral capability
C01.3.1, C01.3.2,

C01.4.1, CO1.4.2,

C01.5.1, C01.5.2

C01.6.1, C01.6.2

C01.4.2, C01.5.2

C01.3.1, CO1.3.2,

CO1.4.1, CO1.4.2

C01.6.1

C01.4.2, C01.5.2,

C01.6.1

C01.4.2, C01.5.2,

C01.6.1, C01.6.

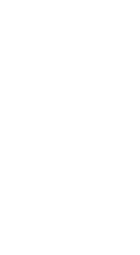

Self-efficacy
$\mathrm{CO} 2.3, \mathrm{CO} 2.4 .1$,

$\mathrm{CO} 2.4 .2, \mathrm{CO} 2.5 .1$ CO2.5.2, CO2.6.1, CO2.6.2,

$\mathrm{CO} 2.4 .1, \mathrm{CO} 2.4 .2$ $\mathrm{CO} 2.5 .1, \mathrm{CO} 2.5 .2$ CO2.6.1
- Feedback

SCT

- Discuss new foods tried at home during past week with Educators and peers during weekly Simple Suppers lesson

- Foods from $\geq 3$ food groups served at Simple Suppers family meals

- Eat Simple Suppers family meals with family and peers

- Children \& caregivers establish weekly goal to engage in preparing wellbalanced meals at home $\geq 1 \mathrm{x} /$ week

- Educators use 4A method to lead caregiver discussions

- Caregivers learn skills to serve nutritious meals/ snacks through discussions, problem solving, games, meal planning, goal setting

Caregivers plan

- Caregivers provided with take-home recipe book of nutritious recipes

- Families receive take-home cooking utensil during each lesson

- Discuss challenges and successes with serving wellbalanced meals/snacks

- Problem solve with peers to overcome challenges

- Simple Suppers group family meals contain $\geq 1 \mathrm{svg}$ from all 5 food groups

- Caregivers observe

Educators serving/engaging children in preparing wellbalanced family meals

- Caregivers plan $\geq 1$ wellbalanced (contains $\geq 1 \mathrm{svg}$ from 3 food groups) family meal per week during each Simple Suppers lesson using skills acquired each lesson

- Learned skills repeated in caregiver family meal planning

- Discuss challenges and successes with serving well-balanced meals/snacks. - Problem solve as a group to overcome challenges

- Plan weekly family meals with peers during Simple Suppers lessons

- Post weekly successes and challenges on Simple Suppers Facebook page. Peers and Educators provide praise/ support/encouragement 
Table 5 Theory-based methods and practical strategies to achieve the change objectives for selected program objectives of the simple suppers intervention (Continued)

\begin{tabular}{|c|c|c|c|c|}
\hline & $\begin{array}{l}\mathrm{CO} 2.3, \mathrm{CO} 2.4 .1 \\
\mathrm{CO} 2.4 .2\end{array}$ & - Modeling & - SCT & $\begin{array}{l}\text { - Educators serve Simple } \\
\text { Suppers group family meals } \\
\text { with } \geq 1 \text { svg from all } 5 \text { food } \\
\text { groups } \\
\text { - Simple Suppers group } \\
\text { family meals eaten with } \\
\text { Educators and peers }\end{array}$ \\
\hline & $\begin{array}{l}\mathrm{CO} 2.3, \mathrm{CO} 2.4 .1 \\
\mathrm{CO} 2.4 .2\end{array}$ & - Mastery experience & • SCT & $\begin{array}{l}\text { - Families eat a well-balanced } \\
\text { family meal during Simple } \\
\text { Suppers group family meals } \\
\text { - Caregivers plan } \geq 1 \text { family } \\
\text { meal } \geq 1 \text { svg from } 3 \text { food } \\
\text { groups each lesson for } \\
\text { upcoming week }\end{array}$ \\
\hline \multirow[t]{2}{*}{ Self-evaluation } & $\begin{array}{l}\text { CO3.4.1, CO3.4.2, } \\
\text { CO3.5.1, CO3.5.2, } \\
\text { CO3.6.1, CO3.6.2, }\end{array}$ & - Self-monitoring & • SCT & $\begin{array}{l}\text { - Set individualized weekly } \\
\text { SMART goal to serve set } \\
\text { number of family meals at } \\
\text { home with } \geq 1 \text { svg from } \geq 3 \\
\text { food groups } \\
\text { - Caregivers plan menus for } \\
\text { the number of family meals } \\
\text { they made their goal for the } \\
\text { upcoming week during } \\
\text { Simple Suppers } \\
\text { - Goals are reinforced by } \\
\text { sharing weekly goal and } \\
\text { planned menus during } \\
\text { Simple Suppers each week. } \\
\text { Educators and peers } \\
\text { provide feedback/assure } \\
\text { appropriateness }\end{array}$ \\
\hline & $\begin{array}{l}\text { CO3.4.2, CO3.5.2, } \\
\text { CO3.6.2 }\end{array}$ & - Feedback & • SCT & $\begin{array}{l}\text { - Discuss previous week's } \\
\text { goal successes and } \\
\text { challenges at beginning of } \\
\text { each Simple Suppers lesson. } \\
\text { Caregivers problem solve } \\
\text { together to overcome } \\
\text { challenges }\end{array}$ \\
\hline $\begin{array}{l}\text { Norms, } \\
\text { modeling, } \\
\text { reinforcement }\end{array}$ & $\mathrm{CO} 4.4, \mathrm{CO} 4.5, \mathrm{CO} 4.6$ & - Facilitation & $\cdot \mathrm{SCT}$ & $\begin{array}{l}\text { - All Simple Suppers group } \\
\text { family meals contain } \geq 1 \text { svg } \\
\text { from all } 5 \text { food groups } \\
\text { - Receive Simple Suppers } \\
\text { cookbook with kid-friendly, } \\
\text { well-balanced meals }\end{array}$ \\
\hline
\end{tabular}

$P O$ performance objective, $C O$ change objective, $H E I$ healthy eating index, Svg serving, SSB sugar sweetened beverage

$A L T$ adult learning theory, SCT social cognitive theory

a Measured by asking the question, "During the past 7 days, how many times did all or most, of your family eat dinner together?"[7]

${ }^{b}$ U.S. Departments of Agriculture and Health and Human Services. Dietary Guidelines for Americans, 2010. 7th ed., Washington, DC. December, 2010 [18]

weight gain [31, 33]. Waist circumference will be measured on all participating children and caregivers with a tape measure at the uppermost lateral border of the hip crest (ilium) [31]. To adjust for expected growth among child participants, child WC z-scores will be determined using CDC age- and sex-specific growth charts [34].

Blood pressure Blood pressure will be assessed on all participating children and caregivers via automated, calibrated BP monitors (Panasonic EW3109W). Age-, sex-, and height-adjusted National Heart, Lung, and
Blood Institute (NHLBI) charts will be used to appropriately classify child BP [35].

Personal determinants We will also assess immediate intervention targets relating to behavioral capabilities. For child participants, food preparation skills and frequency of involvement will be assessed at each data collection point by caregiver completion of an age-appropriate food preparation skills questionnaire designed to assess both skill ability and frequency of involvement in practicing the skill. Working from an existing validated questionnaire designed 
Table 6 Simple Suppers Topics and Goals by Weekly Lesson

\begin{tabular}{lll}
\hline Lesson & Topic & Broad goal for upcoming week \\
\hline 1 & Making family mealtime fun! & $\begin{array}{l}\text { Play } 1 \text { family meal-friendly game during mealtime at } 2 \text { family meal } \\
\text { Occasions }\end{array}$ \\
Use 1 cost-saving strategy to plan and serve 1 well-balanced family meal \\
at 1 family meal occasion
\end{tabular}

to assess child food preparation skills (ability) among 8-10 year olds [7], three versions of the questionnaire (4-5 year old questionnaire; 6-8 year old questionnaire; $9-10$ year old questionnaire) were developed to accurately assess child food preparation skills (ability) according to age appropriateness. Assessment of frequency of involvement in practicing each food preparation skill was added to these modified questionnaires. The resulting questionnaires assessing a child's ability to participate (8 items; 4-point scale; strongly agree to strongly disagree) and frequency of participation (8 items; 5 -point scale; 0 times to $7+$ times) in age-appropriate food preparation skills (during the past 30 days) included 16 items.

Among caregiver participants, menu planning skills and frequency will be assessed at each data collection point by caregiver completion of an existing menu planning questionnaire [36] to evaluate immediate intervention targets relating to behavioral capabilities. The 9-item menu planning questionnaire, which has demonstrated adequate internal consistency $(\alpha=0.68)$ and high testretest reliability (Pearson test-retest $=0.89$ ), asks respondents to rate statements regarding menu planning, meal decision-making, and grocery shopping using a 4-point scale ('never,' 'sometimes', 'often,' 'always').

A key affective variable - caregiver self-efficacy for healthy dietary practices related to family meals - will be assessed using an existing 12-item, 10-point scalar $(0=$ not at all confident; $10=$ extremely confident) questionnaire [37]. The caregiver self-efficacy questionnaire, which will be completed by caregiver participants at each data collection point, has demonstrated high internal consistency $(\alpha=0.88)$ among a sample of caregivers of 4-6 year old children. Tests of internal consistency will be run on all of the aforementioned questionnaires.
Caregivers will also complete a brief food security questionnaire at each data collection point (6-item Short Form of the USDA Home Food Security Survey) [38] and a demographics questionnaire to assess key participant characteristics (age, race/ethnicity, education, employment, income) at baseline.

\section{Home environment}

Family meals Weekly frequency of shared family dinners, shared family breakfasts, television viewing during family meals, and eating family meals in a dining area will be assessed via caregiver reports with 4, 5-point scalar $(0=$ never; $5=7$ times $)$ items from previous family meals research $[39,40]$.

\section{Process measures}

Feasibility (program dose and fidelity) and acceptability will be assessed prospectively throughout the study as process outcomes. Program dose will be assessed by collecting weekly attendance (family and individual level) and tracking presence of caregiver/child dyads at each weekly lesson. Participants who demonstrate irregular attendance and/or discontinue participation will be contacted to learn underlying reasons for absence. To determine program fidelity, a trained observer will complete a program specific fidelity tool at the end of each weekly lesson, which will include a checklist of key program components, activities, and leader characteristics. Acceptability of the program will be measured with a caregiver-completed 5-item satisfaction survey administered at the end of the 10-week program [41]. At the end of programming, interviews will be conducted with 
a subset of caregivers to learn their perceptions of program strengths and weaknesses.

\section{Sample size and data analysis}

Sample size was determined by examining the power of the test for comparing increases in frequency of family meals (day per week) of the intervention and waitlist control group. The data used to estimate power come from a previous pilot study, in which the main outcome of interest was the change in frequency of family dinners prepared and eaten at home together (weekly basis) from baseline to post-intervention [42]. Change in frequency of family dinners was used to power the current study because there is strong evidence that it has a downstream effect on the outcome of interest, child BMI [3, 42-44], and there are no previous studies that show a causal effect of family dinners on BMI. Based on these data, assuming $20 \%$ attrition [42], with an expected effect size of 0.7071 , there will be $80 \%$ power to detect a difference in frequency of family dinners of 3 days per week with 30 families per group for a total sample size of 60 families at $\alpha=0.05$. Because the sample size in the previous pilot study was small and uncertainty about estimated effect size was large, we used a conservative estimate of effect size (i.e., the lower bound of a 95\% confidence interval) for the power calculation.

Data from each of the three cohorts will be pooled and the intervention tested by comparing change (T1T0) in diet quality, anthropometric measures, and blood pressure of child and caregiver participants in the intervention compared to participants in the waitlist control (hypotheses 1.1 and 2.1). Multiple regression models will be used to determine the association between the difference in the response variables of interest between the intervention and control group, controlling for potential confounders (race/ethnicity, income, cohort, intervention dose), from baseline (T0) to 10-week post-test(T1) and 10-week follow-up (T2). For families in which data will be collected on multiple children, the effect of family will also be controlled by including a random effect for family.

Sustainability of intervention effects will be tested by pooling intervention group data from each of the three cohorts, comparing change (T2-T1) in diet quality, anthropometric measures, and blood pressure among intervention group participants at the end of the 10-week follow-up period (hypothesis 1.2 and 2.2). Intervention replication will be assessed by pooling waitlist control group data from each of the three cohorts, comparing post-program change in diet quality, anthropometric measures, and blood pressure among waitlist control participants (T2-T1) to intervention participants (T1-T0). Significance will be set at $p<0.05$.

\section{Discussion}

We may encounter challenges engaging and developing trust with the target population, an issue that is common to intervention research with economically disadvantaged families [45-47]. However, this study was designed to minimize this potential barrier by implementing the intervention at a local faith-based community center, which has established relationships with the target population. In addition, this study will engage current staff from the faith-based community centers to serve as educators in delivering the intervention. Grounding the caregiver component in Adult Learning Theory will further enhance our abilities to engage with families, as this approach is designed to present new information in a non-threatening, approachable way.

Another limitation is the lack of randomization study design. Randomization was not appropriate for this study because preserving sample size and developing trust with the site/participating families was paramount [47-49]. We will overcome this limitation by assessing potential between- group differences at baseline and, if identified, will be controlled for in the analyses.

\section{Acknowledgements \\ We thank our community collaborator Vineyard Community Center (VCC) and VCC staff, Mr. Daniel Nathan (Executive Director) and Ms. Maria Broeckel (Director of Program Development).}

Funding

Cardinal Health Foundation.

Availability of data and material Not applicable.

\section{Authors' contributions}

CG led the conceptual development of the study with input from CR, SSA JSD, TFH, CH, CKM, and KJP. CG and CR led intervention preparations with assistance from SSA, CH, CKM, and KJP. CG and CR took primary

responsibility for writing the manuscript. SSA, JSD, TFH, CH, CKM, and KJP contributed to editing the manuscript. CG, CR, SSA, JSD, TFH, CH, CKM, and KJP read and approved the final manuscript.

\section{Competing interests}

The authors declare that they have no competing interests.

Consent for publication

Not applicable.

\section{Ethics approval and consent to participate}

This study is approved by The Ohio State University Behavioral and Social Sciences Institutional Review Board. Parent consent and parent permission, as well as child assent will be received from participants prior to study enrollment.

\section{Author details}

${ }^{1}$ Department of Human Sciences, Human Nutrition Program, The Ohio State University, 325 Campbell Hall, 1787 Neil Avenue, Columbus, OH 43210, USA. 2Division of Epidemiology, The Ohio State University, 336 Cunz Hall, 1841 Neil Avenue, Columbus, OH 43210, USA. ${ }^{3}$ Division of Nutritional Sciences, Cornell University, 408 Savage Hall, Ithaca, NY 14853, USA. ${ }^{4}$ Division of Nutritional Sciences, Cornell University, 342 MVR, Ithaca, NY 14853, USA.

${ }^{5}$ Department of Statistics, The Ohio State University, 404 Cockins Hall, 1958 Neil Avenue, Columbus, OH 43210, USA. ${ }^{6}$ Department of Human Sciences, Human Nutrition Program, The Ohio State University, 347B Campbell Hall, 
1787 Neil Avenue, Columbus, OH 43210, USA. ${ }^{7}$ Department of Human Sciences, Human Development and Family Science Program, The Ohio State University, 130B Campbell Hall, 1787 Neil Avenue, Columbus, OH 43210, USA. ${ }^{8}$ Department of Human Sciences, Human Nutrition Program, The Ohio State University, 313 Campbell Hall, 1787 Neil Avenue, Columbus, OH 43210, USA.

Received: 22 October 2016 Accepted: 7 December 2016

Published online: 09 January 2017

\section{References}

1. Barlow S. Expert committee recommendation regarding the prevention, assessment, and treatment of child and adolescent overweight and obesity: summary report. Pediatrics. 2007:120:S164-92.

2. Fink SK, Racine EF, Mueffelmann RE, Dean MN, Herman-Smith R. Family meals and diet quality among children and adolescents in North Carolina. J Nutr Educ Behav. 2014;46:418-22.

3. Gable S, Chang Y, Krull JL. Television watching and frequency of family meals are predictive of overweight onset and persistence in a national sample of school-aged children. J Am Diet Assoc. 2007;107:53-61.

4. Rollins BY, Belue RZ, Francis LA. The beneficial effect of family meals on obesity differs by race, sex, and household education: the national survey of children's health, 2003-2004. J Am Diet Assoc. 2010;110:1335-9.

5. Woodruff SJ, Hanning RM, McGoldrick K, Brown KS. Healthy eating index-C is positively associated with family dinner frequency among students in grades 6-8 from Southern Ontario, Canada. Eur J Clin Nutr. 2010;64:454-60

6. Ogden CL, Carroll MD, Fryar CD, Flegal KM. Prevalence of Obesity Among Adults and Youth: United States, 2011-2014. 2015.

7. Fulkerson JA, Rydell S, Kubik MY, Lytle L, Boutelle K, Story M, NeumarkSztainer D, Dudovitz B, Garwick A. Healthy Home Offerings via the Mealtime Environment (HOME): feasibility, acceptability, and outcomes of a pilot study. Obesity (Silver Spring). 2010;18 Suppl 1:S69-74.

8. Fulkerson JA, Neumark-Sztainer D, Story M, Gurvich O, Kubik MY, Garwick A, Dudovitz B. The Healthy Home Offerings via the Mealtime Environment (HOME) Plus study: design and methods. Contemp Clin Trials. 2014;38:59-68.

9. Hammons AJ, Fiese BH. Is frequency of shared family meals related to the nutritional health of children and adolescents? Pediatrics. 2011:127:e1565-74.

10. Fulkerson JA, Neumark-Sztainer D, Hannan PJ, Story M. Family meal frequency and weight status among adolescents: cross-sectional and 5-year longitudinal associations. Obesity (Silver Spring). 2008;16:2529-34.

11. Neumark-Sztainer D, Eisenberg ME, Fulkerson JA, Story M, Larson N. Family meals and disordered eating. Arch Pediatr Adolesc Med. 2008;162:17-22.

12. Neumark-Sztainer D, Wall M, Story M, Fulkerson JA. Are family meal patterns associated with disordered eating behaviors among adolescents? J Adolesc Heal. 2004;35:350-9.

13. Skinner AC, Perrin EM, Skelton JA. Prevalence of obesity and severe obesity in US children, 1999-2014. Obesity. 2016;24:1116-23.

14. Birch L, Arbor A, Savage JS, Ventura A. From Infancy to Adolescence. Can J Diet Pr Res. 2009;68:1-11.

15. Hunter J, Cason K. Kids in the Kitchen. Clemson: 2008.

16. Bartholomew LK, Parcel GS, Kok G. Intervention mapping: a process for developing theory- and evidence-based health education programs. Heal EducBehav. 1998:25:545-63.

17. Bartholomew L, Parcel G, Kok G, Gottlieb N. Planning Health Promotion Programs: An Intervention Mapping Approach. Second. San Francisco: Jossey-Bass; 2011.

18. U.S. Department of Agriculture and U.S. Department of Health and Human Services. Dietary Guidelines for Americans. 7th ed. Washington: 2010.

19. Bandura A. Social cognitive theory. In: Vasta R, (Ed.). Annals of child development. Six theories of child development. Greenwich: JAI Press; 1989;6:pp.1-60.

20. Bandura A. Social Cognitive Theory of Self-Regulation. Organ Behav Hum Decis Process. 1991;50:248-287.

21. Bandura A. Health promotion by social cognitive means. Health Educ Behav. 2004:31:143-64

22. Vella J. Learning to Listen, Learning to Teach: The Power of Dialogue in Educating Adults. San Francisco: Jossey-Bass; 1994.

23. Norris J. From Telling to Teaching: A Dialogue Approach to Adult Learning. North Myrtle Beach: Learning by Dialogue; 1993.

24. Islam SN, Paddock JD, Dollahite JS. Navigating for Success: Quality Staff Training Translates Into Improved Program Participant Outcomes. J Nutr Educ Behav. 2014;47:188-9.
25. Verbon K, Brandt G, Bunsen T, Hobbs H, Johnson F. Promising Practices in Nutrition Education: Choosing the Right Nutrition Education Curriculum for Your Program. 2009.

26. Rogers C, Gunther C. Determining the feasibility and acceptability of a family meals pilot study for families with elementary-aged children. In: Russell Klein Research Symposium. Columbus: 2014.

27. Rogers C, Gunther C. A mixed methods study designed to enhance feasibility and efficacy of a field-tested nutrition education/cooking program for families with preschool-aged children. In: Russell Klein Research Symposium. Columbus: 2015.

28. Bliss R. Researchers produce innovation in dietary recall. Agric Res. 2004;52:10-2.

29. Burrows TL, Martin RJ, Collins CE. A systematic review of the validity of dietary assessment methods in children when compared with the method of doubly labeled water. J Am Diet Assoc. 2010;110:1501-10.

30. Guenther P, Casavale K, Kirkpatrick S, Reedy J. Update of the Healthy Eating Index: HEl-2010. J Acad Nutr Diet. 2014;113:1-20.

31. Lohman T, Roche A, Martorell R. Anthropometric Standardization Reference Manual. Champaign: Human Kinetics Books; 1988.

32. National Health and Examination Survey (NHANES). Anthropometric Procedures Manual. 2007.

33. CDC National Center for Health Statistics: Growth Charts Z-score Data Files. http://www.cdc.gov/growthcharts/zscore.htm. Accessed Mar 2006.

34. Fryar CD, Gu Q, Ogden CL. Anthropometric Reference Data for Children and Adults: United States, 2007-2010. 2012

35. The fourth report on the diagnosis, evaluation, and treatment of high blood pressure in children and adolescents. National High Blood Pressure Education Program Working Group on High Blood Pressure in Children and Adolescents. Pediatrics. 2004;(2 Suppl 4th Report):555-76.

36. Cullen KW, Baranowski T, Rittenberry L, Cosart C, Owens E, Hebert D, De Moor C. Socioenvironmental influences on children's fruit, juice and vegetable consumption as reported by parents : reliability and validity of measures. Public Health Nutr. 2000;3(3):345-356.

37. Bohman B, Nyberg G, Sundblom E, Schäfer Elinder L. Validity and Reliability of a Parental Self-Efficacy Instrument in the Healthy School Start Prevention Trial of Childhood Obesity. Heal Educ Behav. 2013;41:392-6.

38. Bickel G, Nord M, Price C, Hamilton W, Cook J. Guide to Measuring Household Food Security, Revised 2000. Alexandria: 2000.

39. Fulkerson JA, Story MT, Neumark-Sztainer D, Rydell S. Family meals: perceptions of benefits and challenges among parents of 8- to 10-year-old children. J Am Diet Assoc. 2008;108:706-9.

40. Neumark-Sztainer D, Hannan PJ, Story M, Croll J, Perry C. Family meal patterns: Associations with sociodemographic characteristics and improved dietary intake among adolescents. J Am Diet Assoc. 2003;103:317-22.

41. Hesketh K, Campbell K. Interventions to prevent obesity in 0-5 year olds: an updated systematic review of the literature. Obesity. 2010;18:S27-35.

42. Rose AM, Wagner AK, Kennel JA, Miller CK, Holloman C, Pennywitt J, Battista M, Murray RD, Rogers CA, Gunther CW. Determining the Feasibility and Acceptability of a Nutrition Education and Cooking Program for Preschoolers and Their Families Delivered Over the Dinner Hour in a Low-Income Day Care Setting. Infant, Child, Adolesc Nutr. 2014;6:144-51.

43. Fulkerson JA, Kubik MY, Story M, Lytle L, Arcan C. Are There Nutritional and Other Benefits Associated with Family Meals Among At-Risk Youth? J Adolesc Heal. 2009;45:389-95.

44. Taveras EM, Rifas-Shiman SL, Berkey CS, Rockett HRH, Field AE, Frazier AL, Colditz GA, Gillman MW. Family dinner and adolescent overweight. Obes Res. 2005:13:900-6.

45. Sen B. Frequency of Family Dinner and Adolescent Body Weight Status Evidence from the National Longitudinal Survey of Youth, 1997. Obesity. 2006;14:2266-76.

46. Corbie-Smith G, Thomas S, St George D. Distrust, race, and research. Arch Intern Med. 2002;162:2458-63.

47. Goode T, Harrison S. Cultural Competence in Primary Health Care: Partnerships for a Research Agenda. 2000.

48. Yancey AK, Ortega AN, Kumanyika SK. Effective Recruitment and Retention of Minority Research Participants. Annu Rev Public Health. 2006:27:1-28.

49. Brannon EE, Kuhl ES, Boles RE, Aylward BS, Ratcliff MB, Valenzuela JM, Johnson SL, Powers SW. Strategies For Recruitment and Retentionof Families fom Low-Income, Ethnic Minority Backgrounds in a Longitudinal Study of Carefiver Feeding and Child Weight. Child Heal Care. 2013:42:198-213. 